\title{
Androgen and glucocorticoid levels reflect seasonally occurring social challenges in male redfronted lemurs (Eulemur fulvus rufus)
}

\author{
Julia Ostner • Peter Kappeler • Michael Heistermann
}

Received: 11 December 2006 /Revised: 24 August 2007 / Accepted: 27 August 2007 / Published online: 19 September 2007

(C) Springer-Verlag 2007

\begin{abstract}
Intense reproductive competition and social instability are assumed to increase concentrations of glucocorticoids and androgens in vertebrates, as a means of coping with these challenges. In seasonally breeding redfronted lemurs (Eulemur fulvus rufus), the mating and the birth season and the associated increased male competition are predicted to pose such reproductive challenges. In this paper, we investigate seasonal variation in hormone excretion in male redfronted lemurs, and examine whether this variation is associated with social or ecological factors. Although dominance status has been shown to affect individual stress levels across many taxa, we predicted no rank-related differences in glucocorticoids for redfronted lemurs because relatively equal costs are associated with both high and low rank positions (based on patterns of rank acquisition/maintenance and threats toward subordinates). Over a 14-month period, we collected behavioral data (1843 focal hours) and 617 fecal samples from 13 redfronted lemur males in Kirindy Forest/Madagascar. We found no general rank-related pattern of testosterone or glucocorticoid
\end{abstract}

Communicated by J. Setchell

J. Ostner $(\bowtie)$

Integrative Primate Socio-Ecology,

Max Planck Institute for Evolutionary Anthropology,

Deutscher Platz 6,

04103 Leipzig, Germany

e-mail: ostner@eva.mpg.de

P. Kappeler

Department of Behavioral Ecology and Sociobiology,

German Primate Center,

Göttingen, Germany

M. Heistermann

Department of Reproductive Biology, German Primate Center,

Göttingen, Germany excretion in this species. Both hormones were excreted at significantly higher levels during the mating and the birth season, despite social stability during both periods. The elevated mating season levels may be explained by increased within-group reproductive competition during this time and are in line with previous studies of other seasonally reproducing primates. For the birth season increase, we propose that the predictable risk of infanticide in this highly seasonal species affects male gonadal and adrenal endocrine activity. We evaluate alternative social and ecological factors influencing the production of both hormone classes and conclude based on our preliminary investigations that none of them can account for the observed pattern.

Keywords Glucocorticoids · Androgens .

Eulemur fulvus rufus · Sexual competition · Seasonality . Stress

\section{Introduction}

Androgens and glucocorticoids from the testes and adrenals, respectively, serve several adaptive functions in male vertebrates. Androgens, in particular testosterone, influence multiple aspects of male reproductive morphology, physiology, and behavior, such as formation of secondary sexual characters, promotion of spermatogenesis, and expression of mating behavior (Dixson 1998; Rommerts 1998). Testosterone has also been linked to male aggressive behavior in response to reproductive challenges where increased testosterone output supports a period of heightened aggression during territory defense or mate guarding (Wingfield et al. 1990, 2000). Similarly, increased glucocorticoid secretion may be viewed as an adaptive stress response to challenging situations (Sapolsky 2002). Circulating glucocorticoids 
accelerate the carbohydrate metabolism and lead to an increased availability of glucose in the bloodstream, which in turn helps to counter stressors in short-term challenges (Nelson 2000).

Such challenging or stressful factors may be ecological or social events that animals face in their environment. Ecological stressors such as adverse climatic factors, low food availability, or high predation pressure have all been associated with increased levels of glucocorticoids in primates (Cavigelli 1999; Muller and Wrangham 2004; Weingrill et al. 2004; Pride 2005a; Engh et al. 2006) and vertebrates in general (Romero et al. 2000; Pereira et al. 2006; Ylönen et al. 2006; Angelier et al. 2007). At the same time, social instability due to immigration events or rank reversals may lead to a stress response (Beehner et al. 2005; Bergman et al. 2005). Immigration of adult males, in particular, may represent a source of stress, as the newcomer(s) may not only challenge rank positions (Alberts et al. 1992; Bergman et al. 2005) but, in the most extreme case, may oust the resident male(s) (Pope 1990; Ostner and Kappeler 2004). Immigration events are also often associated with an increased risk of infanticide posed by the immigrating male(s) (Borries 1997; Crockett and Janson 2000; Fedigan 2003) which is another potential source of stress for both males (Bergman et al. 2005) and females (Beehner et al. 2005).

In this study, we investigate seasonal and social influences on glucocorticoid and testosterone excretion in redfronted lemur males (Eulemur fulvus rufus). Redfronted lemurs live in relatively small multimale-multifemale groups in a highly seasonal habitat with distinct annual mating and birth seasons (Overdorff 1998; Ostner and Kappeler 1999). In the study population at Kirindy Forest males within a group can be classified as either the dominant male or one of several subordinate males, with the dominant male being able to outrank all other group members including all adult females (Ostner and Kappeler 1999; Ostner et al. 2002). Reproductive skew within these groups is relatively high, with the dominant male siring the vast majority of infants (Wimmer and Kappeler 2002). Rank-related costs (sensu relative allostatic load; Goymann and Wingfield 2004) of males should be relatively equal as both rank classes face only a moderate level of stress. A dominant male needs to aggressively fight for his rank, but once he is dominant, the position is relatively easily maintained as rank positions are rarely challenged. A subordinate male on the other hand faces constant but only low level threats from dominants, whose aggression he cannot escape due to the cohesive nature of redfronted lemur groups (Ostner and Kappeler 1999). We therefore expect no rank-dependent difference in glucocorticoid levels.

To examine the seasonal pattern of androgens in this population we investigated the monthly variation of andro- gen excretion in a previous study and found pronounced increases in male androgen levels in the months most closely associated with the mating and the birth season (Ostner et al. 2002). While an androgen rise during the mating season was expected in terms of reproductive competition, the latter was unexpected and interpreted as a potential preparatory mechanism of males to stay aggressive during a period of increased infanticide risk (Ostner et al. 2002). Because redfronted lemur infants are weaned early (on average after 135 days; Kappeler and Pereira 2003), the critical time window for infanticide (and thus the potential source of stress) is brief and predictable due to the tight seasonal reproduction. To deepen our understanding of redfonted lemur male competition, we investigate seasonal patterns of hormone excretion again, this time focusing on glucocorticoids. Specifically, we predict that males respond to the seasonally occurring challenges of sexual competition by increased levels of glucocorticoids during the mating and birth season, respectively, mirroring the seasonal pattern of androgen excretion. To do so, we also reanalyze androgen excretion in the samples from our previous study based on reproductive season rather than monthly variation (Ostner et al. 2002).

Elevated glucocorticoid levels may also be influenced by other factors, such as challenges from within the group or by neighboring groups. At Kirindy, redfronted lemur home ranges overlap extensively between neighboring groups (average overlap area is $43 \%$ ) and groups meet regularly (Ostner and Kappeler 2004). All adult males generally engage in intergroup aggression (Ostner unpublished data). We investigate the impact of these alternative factors, using the rate of within-group aggressive interactions as well as the rate of intergroup encounters as measures for potential stressors. Alternatively, the predicted increase in hormone excretion during the birth season might also be a response to ecological factors. To address this hypothesis, we investigate patterns of diet composition and feeding behavior across seasons.

\section{Materials and methods}

Study site and population

The study was carried out on a population of redfronted lemurs (Eulemur fulvus rufus). The study site is a 60-ha area locally known as CS7, which is part of the German Primate Center (DPZ) field station within the Kirindy/CFPF forest concession, about $60 \mathrm{~km}$ northeast of Morondava, western Madagascar. This area of dry deciduous forest is characterized by a pronounced seasonality with a hot rainy season from November to March/April and a cooler dry season between May and October (for a detailed description 
of the area, see Sorg et al. 2003). Redfronted lemurs are preyed upon by the largest Malagasy carnivore, the fossa (Cryptoprocta ferox), and several birds of prey, including the harrier hawk (Polyboroides radiatus; Goodman et al. 1993; Rasoloarison et al. 1995). Beginning in 1996, all animals from seven groups in the study area have been captured and marked individually with nylon or radio collars (Biotrack, Wareham, Dorset, UK) and have been subject to regular censuses (Ostner and Kappeler 2004). This study covers the period from May 1999 to June 2000, thus including two mating (4 weeks in May/June) and one birth seasons (4 weeks in September/October).

\section{Study period and focal groups}

Behavioral data and fecal samples were collected from all adult males $(n=13)$ of three focal groups (groups A, B and F) living in adjacent home ranges (Ostner and Kappeler 2004). Data of groups A and B were collected throughout the entire 14-month study. In the mating season of 2000, we added a third group (group F). Group composition and important demographic events are listed in Table 1. Due to the high degree of seasonality in reproduction, we split the data into five distinct reproductive periods (Table 2): two mating seasons, covering the 4-week period when all conceptions took place. Given a gestation period of 121 days (Ostner and Heistermann 2003), we defined gestation as the 4-month period after the mating season and the birth season as a 4 -week period starting 4 months after the first day of the preceding mating season. All births occurred during this period. The period after the birth season was defined as lactation period, and given a mean weaning age of 135 days for E. fulvus (Kappeler and Pereira 2003), was defined as the four and a half months after the birth season.

\section{Behavioral observations}

Data on agonistic behavior were collected from all adult males of the three groups, using 1-h focal animal sampling (Altmann 1974), yielding a total of $1,843 \mathrm{~h}$ of focal observational data from the five seasons (Table 2). In gen- eral, focal animal data were collected continuously on one group for an entire day before continuing with another group the following day. Data on male rank relationships, as well as rates of male-male conflicts are based on this data set. Interactions were defined as agonistic if at least one member of a dyad showed aggressive (lunge, charge, cuff, grab, bite, chase) or submissive (be displaced, cower, jump away, flee) behavior (Pereira and Kappeler 1997; Ostner and Kappeler 1999). Male rank was determined on the basis of "decided" interactions (Hausfater 1975). Within each group, a central, dominant male, who is frequently involved in aggressive interactions and is winner in all decided conflicts, could be unambiguously distinguished from all other (subordinate) males (Ostner and Kappeler 1999). Within the class of subordinates, males could also be aligned along a dominance hierarchy, but conflicts were much less frequent compared to conflicts involving the dominant male, and these conflicts were more often undecided. Rank reversals among subordinate males, i.e., a lower ranking male winning a decided conflict against a higher-ranking male, were also uncommon. Male rank relations were stable throughout the study period with two exceptions: a short-term instability due to changes in group composition in group B during February/March 2000 (see Table 1) and rank reversals among resident males in group $\mathrm{F}$ (eventually leading to the replacement of the alpha male by a former subordinate male; for details, see Ostner et al. 2002).

We used hourly rate of aggression per individual male as a measure of within group challenge and the hourly rate of intergroup encounter as a proxy for between-group competition. All occurrence data on intergroup encounters were collected throughout the study period; the hourly rate is based on the time spent with the group. An encounter with a specific group was counted once for a given day and event, independent of the duration or quality of the encounter. In addition to the continuous focal animal sampling, the activity of the focal animal was recorded instantaneously every $10 \mathrm{~min}$. Instantaneous sampling included all behavioral states (feeding, resting, moving, etc.), as well as the food item (fruit, flower, bud, leaf, animal matter, etc.) and plant species consumed in case of feeding behavior.
Table 1 Group composition, period of data collection and demographic events of study groups

\begin{tabular}{lllcl}
\hline Group & $\begin{array}{l}\text { Number } \\
\text { of males }\end{array}$ & $\begin{array}{l}\text { Number } \\
\text { of females }\end{array}$ & Data collection & Demographic events \\
\hline A & $4-5$ & 2 & $\begin{array}{c}\text { May 1999- } \\
\text { Jun 2000 } \\
\text { May 1999- }\end{array}$ & $\begin{array}{l}\text { Feb 2000: one adult male immigrated } \\
\text { Jun 2000 }\end{array}$ \\
B & $3-4$ & $2-3$ & $\begin{array}{l}\text { Feb 2000: two adult males emigrated } \\
\text { Jun 2000 }\end{array}$ & Jun 2000: Alpha male replacement within group \\
F & 3 & 2 & &
\end{tabular}


Table 2 Observation periods, focal hours and number of fecal samples collected

\begin{tabular}{llccc}
\hline Season & Time period & Number of samples & Number of males & Focal hours \\
\hline Mating 1999 & 16 May 1999-15 Jun 1999 & 101 & 8 & 429 \\
Gestation & 16 Jun 1999-15 Sep 1999 & 172 & 8 & 382 \\
Birth & 16 Sep 1999-15 Oct 1999 & 57 & 8 & 155 \\
Lactation & 16 Oct 1999-28 Feb 2000 & 199 & 8 & 578 \\
Mating 2000 & 01 Jun 2000-30 Jun 2000 & 88 & 10 & 299 \\
\hline
\end{tabular}

Collection of fecal samples and evaluation of a possible storage effect on hormone levels

To assess individual testosterone and glucocorticoid profiles, fecal samples were collected from all males of the three study groups (Table 2). In groups A and B, samples were collected during all five reproductive periods, whereas in group F, samples were collected only during the mating season in 2000. Overall frequency of sample collection varied depending on reproductive period from every third day (mating seasons) to every fifth day (gestation, lactation, birth season), and males were sampled independent of sampling success for other males, yielding a total of 617 samples (10-89 samples per male). Samples were collected immediately after defecation and preserved in $8 \mathrm{ml}$ absolute ethanol until hormone analysis (Kraus et al. 1999).

To evaluate if our storage of redfronted lemur fecal samples in ethanol potentially affected the fecal testosterone and glucocorticoid concentrations as has been demonstrated for other species (Khan et al. 2002; Hunt and Wasser 2003), we post hoc tested fecal hormone levels as a function of storage duration. For this, we collected 18 fecal samples from different individuals of our study population and, after extensive homogenization by hand, divided each sample into three parts and stored them in ethanol as described above. Aliquots were kept for 60 days at the field station at ambient temperatures before being transported to the laboratory for hormone analysis. The first set of samples was extracted immediately after arrival in the lab while the other two sets were extracted after 150 and 240 days (relative to their time of collection) of storage at field/room temperature. After each extraction, extracts were stored at $-20^{\circ} \mathrm{C}$ before all extracts were analyzed at the end of the experiment. For neither the testosterone nor the glucocorticoid measurement we found a significant effect of storage duration on fecal hormone levels (Table 3).

\section{Hormone analyses}

Fecal samples were extracted as previously described by Ostner et al. (2002). From these extracts, concentrations of immunoreactive testosterone were measured using a validated microtiterplate enzymeimmunoassay as has been previously reported (Ostner et al. 2002).
Concerning the fecal glucocorticoid measurements, unfortunately, we could not conduct an adrenocorticotropic hormone (ACTH) challenge test for validation as captive animals for such an experiment were not available. Furthermore, carrying out this procedure on our study population of redfronted lemurs would have been too invasive. We therefore took the approach of applying a group-specific assay for the measurement of $5 \beta$-reduced cortisol metabolites $(3 \alpha, 11$-oxo-CM) given that (a) these compounds are abundant in the feces of mammals (Möstl et al. 2002; Ganswindt et al. 2003; Heistermann et al. 2006) and (b) that their measurement has been shown to provide reliable information on endocrine adrenal function in nonprimate (Möstl et al. 2002; Ganswindt et al. 2003) and many primate species (Heistermann et al. 2006), including the sifaka (Propithecus verreauxi), a related lemur species (Fichtel et al. 2007). In addition, we performed highperformance liquid chromatography (HPLC) analysis on fecal extracts as described in Heistermann et al. (2006) to obtain information on the characteristics of metabolites

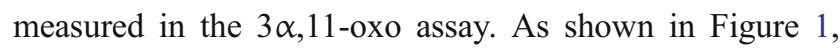
almost all immunoreactivity eluted between fractions 9 and 31 , at positions at which in other primate species major metabolites of cortisol are detected (Heistermann et al. 2006). The similarity between HPLC glucocorticoid immunoreactivity profiles from the redfronted lemur sample and those derived from fecal samples of other primate species strongly (although indirectly) suggests that the $3 \alpha, 11$-oxo assay measures similar cortisol metabolites, and we are thus confident that the assay reliably detects glucocorticoid output in redfronted lemurs.

For measurement of immunoreactive $3 \alpha, 11$-oxo-CM, fecal extracts were usually diluted 1:300 in assay buffer (0.04 M PBS, pH 7.2) and $50 \mu 1$ aliquots were measured by microtiterplate enzymeimmunoassay according to the meth-

Table 3 Effect of storage of fecal samples in ethanol on testosterone and glucocorticoid concentrations

\begin{tabular}{lcccc}
\hline Hormone & \multicolumn{2}{l}{ Duration of storage } & \multirow{2}{*}{$P$ value } \\
\cline { 2 - 4 } & 60 days & 150 days & 240 days & \\
\hline Testosterone & $50.0 \pm 8.2$ & $47.5 \pm 8.7$ & $47.4 \pm 8.4$ & 0.984 \\
$3 \alpha, 11$-oxo-CM & $848.0 \pm 139.1$ & $871.5 \pm 204.9$ & $758.7 \pm 82.6$ & 0.823 \\
\hline
\end{tabular}

Data represent mean \pm SEM (ng/g) 


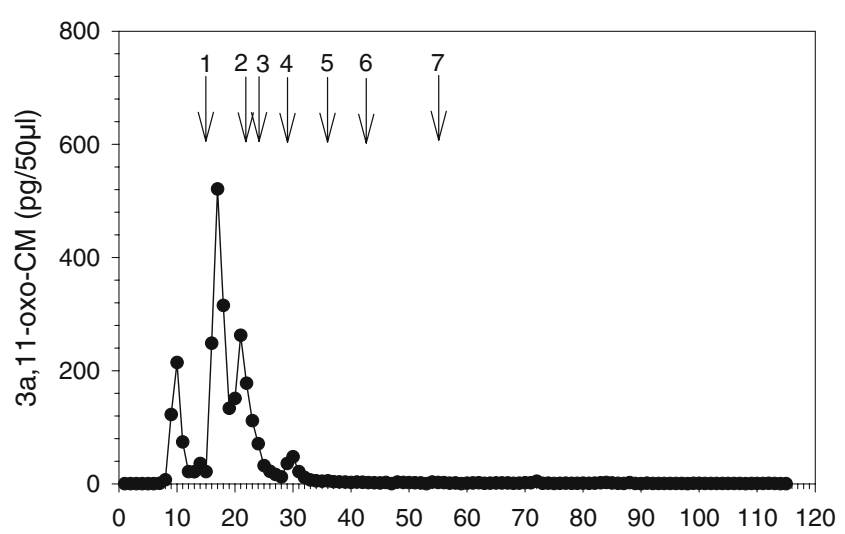

Fig. 1 HPLC profile of immunoreactivity detected with the $3 \alpha, 11-$ oxo assay in a redfronted lemur fecal extract. Arrows indicate elution positions of 1 cortisol (14-15), 2 corticosterone (22), $311 ß-$ hydroxyetiocholanolone (24-25), 4 11-oxo-etiocholanolone (29-30), $55 \beta$-androstane,3,11,17-trione, 6 testosterone $(42-43)$ and 7 androstenedione, dehydroepiandosterone (55-56). In this HPLC system, cortisol metabolites elute between fractions 9-31 (see Heistermann et al. 2006)

od described by Palme and Möstl (1997) and Möstl et al. (2002). Serial dilutions of fecal extracts from samples of different males gave displacement curves parallel to that obtained for the standard. Sensitivity of the $3 \alpha, 11$-oxo-CM assay at $90 \%$ binding was $3 \mathrm{pg}$, and intra- and interassay coefficients of variation of high and low value quality controls were $7.2 \%(n=16)$ and $12.1 \%(n=62)$ (high) and $10.3 \%(n=16)$ and $16.9 \%(n=60$; low $)$, respectively.

\section{Data analyses}

Glucocorticoid concentrations across storage times were tested for significant differences using a one-way ANOVA. Values of hormone concentrations were not normally distributed and therefore log-10 transformed (Fowler and Cohen 1990). Throughout the text, if not stated otherwise, we refer to transformed values when mentioning hormone levels. We calculated a mean hormone value for each male and then took the mean for each grouping in each analysis. For an overall analysis of the relationship between rank and hormone levels, we averaged samples from each male collected during the mating seasons and compared these mean values of androgen and glucocorticoid concentrations between both groups of males (one dominant and several subordinates for each group) using Student's $t$ test for dependent samples. In an additional step, we analyzed individual variation in hormone excretion separately for the males of groups A and B using year-round data instead of focusing on the mating season. For this analysis, we used only stable periods (no changes in dominance hierarchy), hence all five periods in group A (but excluding one male, which died early in the study) and the first four periods in group B (afterwards the group experienced several emigra- tions and immigrations as well as rank changes, see Table 1). For these comparisons, we applied one-way ANOVA and, if applicable, Tukey HSD post hoc tests implemented in Statistica 7. We used a general linear mixed model (GLMM) to analyze the effect of a categorical variable (reproductive season) on a dependent continuous variable, i.e., glucocorticoid or androgen excretion. GLMMs can be viewed as an extension of general linear models accounting for repeated measurement of the same individual by including subject as a random factor in the model (Pinheiro and Bates 2000). Compound symmetry was selected as covariance structure for the random factor. GLMM analyses were carried out using SPSS 11.5. For post hoc analyses, we used pair-wise comparisons. We also used a GLMM to investigate effects of social factors, e.g., intergroup encounter rate or rate of within-group aggression, on individual hormone excretion. Paired samples $t$ tests were used to compare hormone levels of males between the birth season and the postbirth season. The allocation of feeding time to different food categories was compared between seasons using Kolmogorov-Smirnov2-samples tests (KS-tests). All tests were applied two-tailed with an alpha level of 0.05 .

\section{Results}

Testosterone and glucocorticoid excretion in relation to social status

Mean mating season excretion of testosterone and glucocortioids did not vary significantly between males of different social classes if pooled across groups $(t$ test: $N_{\text {dom }}=4, N_{\text {sub }}=11$; testosterone: mean $_{\text {dom }}=2.22, \mathrm{SD}=0.07$, mean $_{\text {sub }}=2.12, \mathrm{SD}=0.20, t=0.96, p=0.35$; glucocorticoids: mean $_{\text {dom }}=3.09, \mathrm{SD}=0.18$, mean $_{\text {sub }}=3.15, \mathrm{SD}=0.16$, $t=-0.66, p=0.52$ ). However, comparing excreted hormone levels on an individual basis and for both groups separately, we found a significant effect of rank on glucocorticoid excretion in both groups (one-way ANOVA: group A: $F(3$, $282)=3.50, P<0.02)$; group $\mathrm{B}: F(3,272)=6.34, P<0.001$; Fig. 2a and b). Subordinate males across both groups, as well as within the groups, showed similar glucocorticoid levels. Values of dominant males, however, differed from those of subordinates, with the dominant male of group A having the lowest output, deviating significantly $(P<0.05)$ from both the second and third ranking males (all other comparisons: n.s.), whereas in group B, glucocorticoid levels were highest in the dominant male and decreased with decreasing rank. The difference between the dominant male and the lowest ranking male in group $\mathrm{B}$ was significant $(P<0.01)$, and there was a trend for a significant decrease from the dominant male to the second and third ranking male, respectively $(P<$ 0.1 ; all other comparisons: n.s.). 

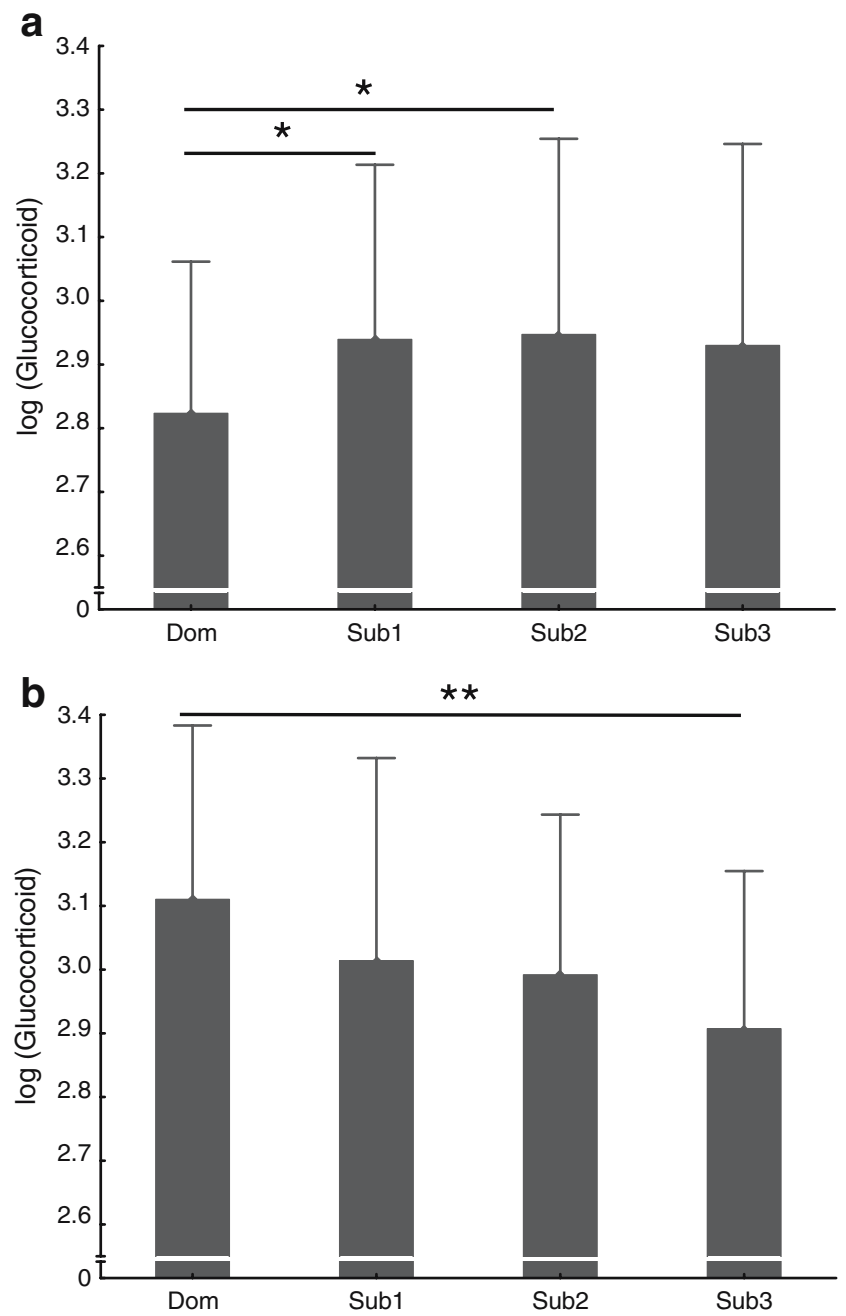

Fig. 2 a Mean (+SD) glucocorticoid levels (log-10 transformed) of four adult males of group A. Samples from all five seasons. Untransformed values are in ng/g dry weight. Males are aligned according to their individual ranks. Note, however, that the clearest distinction is between the dominant male and the class of subordinates. Within the subordinate class only subtle rank differences existed. One-way ANOVA: $F(3,282)=3.50, P=0.016$. Tukey post hoc tests: single asterisk, $P<0.05$. All other comparisons are not significant. b Mean (+SD) glucocorticoid levels (log-10 transformed) of four adult males of group B. Samples from first four seasons (mating season 2000 excluded due to social instabilities within the group). Untransformed values are in $\mathrm{ng} / \mathrm{g}$ dry weight. Males are aligned according to their individual ranks. Note, however, that the clearest distinction is between the dominant male and the class of subordinates. Within the subordinate class only subtle rank differences existed. One-way ANOVA: $F(3,272)=6.34, P=0.0004$. Tukey post hoc tests: double asterisk, $P<0.01$. All other comparisons are not significant. Dom, dominant male; $S u b$, subordinate male

Testosterone and glucocorticoid excretion in relation to season

Male testosterone excretion differed significantly in relation to reproductive season, with highest levels being found during the birth season, intermediate concentrations during the mating seasons, and lowest levels during the gestation and lactation period (GLMM: $F(4,28)=14.71 ; P<0.0001$; Fig. 3).

Pair-wise comparisons revealed that birth season testosterone levels were significantly higher compared to those recorded in all other periods, and that both mating season levels were significantly higher than those found during the gestation and lactation period (Table 4). In contrast, there was neither a significant difference in $\mathrm{T}$ levels between the two mating seasons, nor between gestation and lactation (Table 4).

As with testosterone, glucocorticoid levels were also significantly influenced by reproductive season (GLMM: $F$ $(4,28)=17.01 ; P<0.0001 ;$ Fig. 4). Specifically, and parallel to testosterone, glucocorticoid levels during the mating seasons, as well as the birth season, were significantly higher than those during the periods of gestation and lactation (Table 5). As with testosterone, there was neither a significant difference in glucocorticoid levels between the two mating seasons, nor between the gestation and lactation period (Table 5).

Testosterone and glucocorticoid excretion in relation to social and ecological influences

We analyzed the effects of potentially challenging, stressful factors on hormone excretion. We used hourly rate of aggression as the within-group measure and hourly rate of group encounters as the between-group measure (Table 6). Neither measure of aggression showed a general increase during the times with higher hormone excretion, i.e., mating and birth season, and neither factor was a significant predictor of testosterone or glucocorticoids excretion in a GLMM (Table 7). Hence, the pattern of hormone excretion

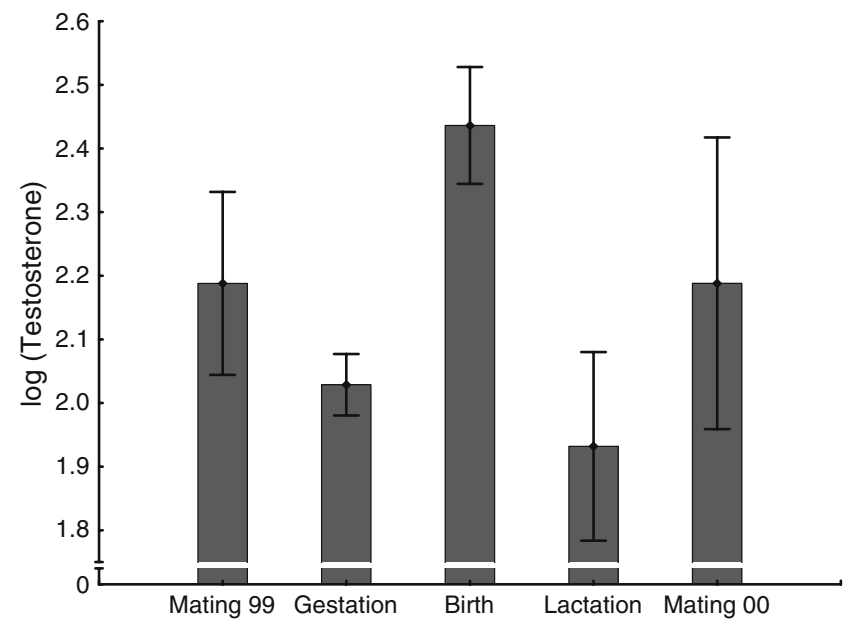

Fig. 3 Log-10 transformed testosterone levels in relation to reproductive season (means and SD of eight to ten males depending on season). Untransformed values are in ng/g dry weight. GLMM: $F(4$, $28)=14.71 ; P<0.0001$. For samples sizes see Table 2, for results of post hoc comparisons see Table 4 
Table $4 P$ values of pair-wise comparisons of mean differences in log 10 transformed testosterone values across different reproductive seasons

\begin{tabular}{llllll}
\hline Season & Mating 99 & Gestation & Birth & Lactation & Mating 00 \\
\hline Mating 99 & - & - & - & - & - \\
Gestation & 0.036 & - & - & - & - \\
Birth & 0.002 & 0.000 & - & - & - \\
Lactation & 0.001 & 0.181 & 0.000 & - & - \\
Mating 00 & 0.931 & 0.035 & 0.001 & 0.001 & - \\
\hline
\end{tabular}

was not simply a general function of increased inter- or intragroup aggression.

We examined whether ecological factors (e.g., changes in feeding behavior or diet composition) other than events related to the birth season might be responsible for the increase in male androgen and glucocorticoid levels during this time period. We compared the hormone mean for each male during the 4-week birth season with the corresponding value during the 4 weeks immediately following it and investigated in parallel whether changes in feeding time and diet occurred. Levels of both hormones significantly decreased from the birth period to the early post birth period (paired samples $t$ test: testosterone: $n=8, t=2.68, P<$ 0.05; glucocorticoids: $n=8, t=3.93, P<0.01$; Fig. 5), but neither amount time spent feeding, nor the relative composition of food items in the diet changed between the two 4 -week time blocks. Males fed during $18 \%$ of activity time in the birth and $19 \%$ in the postbirth period (155 and 118 focal animal hours, respectively). Fruits were eaten $75 \%$ of feeding time during the birth season and $72 \%$

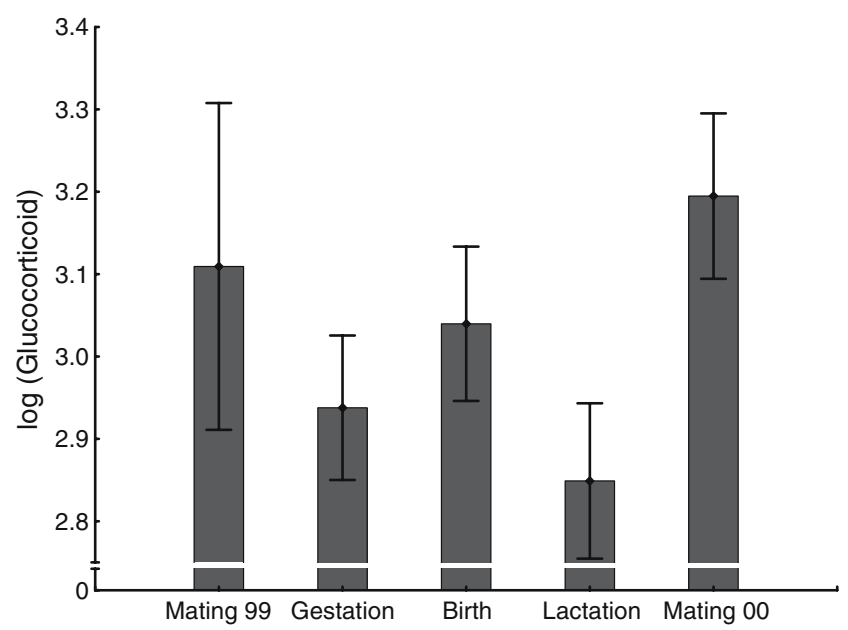

Fig. 4 Log-10 transformed glucocorticoid levels in relation to reproductive season (means and SD of eight to ten males depending on season). Untransformed values are in $\mathrm{ng} / \mathrm{g}$ dry weight. GLMM: $F$ $(4,28)=17.01 ; P<0.0001$. For samples sizes see Table 2 , for results of post hoc comparisons see Table 5
Table $5 P$ values of pair-wise comparisons of mean differences in log 10 transformed glucocorticoid values across different reproductive seasons

\begin{tabular}{llllll}
\hline Season & Mating 99 & Gestation & Birth & Lactation & Mating 00 \\
\hline Mating 99 & - & - & - & - & - \\
Gestation & 0.001 & - & - & - & - \\
Birth & 0.210 & 0.030 & - & - & - \\
Lactation & 0.000 & 0.056 & 0.000 & - & - \\
Mating 00 & 0.071 & 0.000 & 0.003 & 0.000 & - \\
\hline
\end{tabular}

during the postbirth period (KS-test: $N_{\mathrm{BS}}=N_{\text {Post-BS }}=6$, max. positive difference $=0.167$, max. negative difference $=-0.33$, n.s.; Fig. 6). In both seasons, the fruit of one particular species, Astrotrichilia asterotricha (Meliaceae, vernacular name: Sarihompy), made up for over $50 \%$ of total feeding time.

\section{Discussion}

Our study revealed no general rank-related pattern of testosterone or glucocorticoid excretion in male redfronted lemurs. Males of both rank classes had similar levels of both hormones, which is in accordance with expectations based on social dominance relations in this species. The most interesting finding of the study was the seasonal pattern of hormone excretion. Testosterone and glucocorticoids were both excreted at high levels during the mating season as well as during the short annual birth season. We will discuss these results below, highlighting possible social as well as ecological factors that may underlie this pattern.

Relationship between social status and hormone excretion

Despite the multitude of studies on the relationship between stress physiology and social status in vertebrates, no clear pattern has emerged (Creel 2001). Two recent publications, one on mammals and birds in general (Goymann and

Table 6 Hourly rates of within group aggression (mean and standard deviation of 8-10 males) and intergroup encounters (mean of 2-3 study groups) across the five reproductive seasons

\begin{tabular}{|c|c|c|c|}
\hline \multirow[t]{2}{*}{ Season } & \multicolumn{2}{|c|}{ Within group aggression } & \multirow{2}{*}{$\begin{array}{l}\text { Inter-group encounters } \\
\text { Mean }\end{array}$} \\
\hline & Mean & SD & \\
\hline Mating 99 & 0.47 & 0.34 & 0.07 \\
\hline Gestation & 0.30 & 0.26 & 0.12 \\
\hline Birth & 0.45 & 0.32 & 0.06 \\
\hline Lactation & 0.49 & 0.21 & 0.08 \\
\hline Mating 00 & 0.68 & 0.52 & 0.04 \\
\hline
\end{tabular}


Table 7 Results of GLMM on social influences on hormone excretion

\begin{tabular}{llllll}
\hline Fixed factor & \multicolumn{2}{l}{ Testosterone } & & \multicolumn{2}{l}{ Glucocorticoid } \\
\cline { 2 - 3 } \cline { 5 - 6 } & $\mathrm{F}$ & $\mathrm{P}$ & & $\mathrm{F}$ & $\mathrm{P}$ \\
\hline $\begin{array}{l}\text { hourly rate of within group } \\
\text { aggression }\end{array}$ & 1.717 & 0.201 & & 0.009 & 0.927 \\
$\begin{array}{l}\text { Hourly rate of inter-group } \\
\text { encounter }\end{array}$ & 3.247 & 0.090 & 0.263 & 0.661 \\
\hline
\end{tabular}

Wingfield 2004) and one on primates in particular (Abbott et al. 2003), set out to identify the bases for the observed variation. Both approaches used similar assumptions regarding the intensity of stress in either dominance position, i.e., the costs of acquiring and maintaining a high rank and the frequency and intensity of aggression a subordinate is exposed to. Based on our observed characteristics of rank acquisition and rank relationships in redfronted lemurs, we assigned similar costs for both rank classes and consequently predicted no rank-related differences in glucocorticoid output. This prediction was confirmed when data from dominant and subordinate males were pooled across groups, indicating that inequality of the different rank positions was apparently not pronounced enough to lead to significant rank effects in glucocorticoids.

Looking at the two groups separately, we found glucocorticoid levels to be similar between subordinate males (both within a group and between groups). At the same time, glucocorticoid excretion of dominant males differed markedly between groups, as well as between the dominant male and the subordinates of his group. In one group, the dominant male exhibited highest glucocorticoid levels, whereas the opposite was found in the second group. Given the lack of a general effect of rank on male glucocorticoid output in this population, it may be that other more subtle or individual factors affect glucocorticoid levels of individual males, irrespective of rank. In this respect, group instability has been proposed as one of the main predictors of male glucocorticoids levels in both dominant and subordinate individuals (Sapolsky 1983, 1993). Whether this could provide a post hoc explanation for the contrasting findings on the relationship between male rank and glucocorticoid output in the two study groups is not clear. Group composition was similar in both study groups (i.e., the number of subordinate males was the same and there were no obvious rank challenges in either of the two), but group B was characterized by frequent excursions by the two natal subordinate males, culminating in their emigration in February 2000 (promptly followed by the immigration of an older male, which eventually became dominant in this group a few months later). It is therefore possible that this group was unstable a long time before it became evident to the observer. Because our results demonstrated the lack of a consistent rank-glucocorticoid relationship, further studies are needed on more groups to investigate individual and life history effects, such as age-dependent changes in glucocorticoid excretion.

Seasonal effects on testosterone and glucocorticoid output

Both, glucocorticoids and testosterone, showed similar seasonal patterns with significant increases during both the mating and the birth season. The mating season increase in testosterone was expected, given the importance of testosterone in triggering sexual and aggressive behavior as well as physiological processes vital for reproduction (Wickings et al. 1986; Baum 2002). In this respect, our results compare well with data on other seasonally reproducing primate species (Kraus et al. 1999; Barrett et al. 2002; Lynch et al. 2002; Bales et al. 2006; Drea 2007). Because the mating season is a predictable time of increased energetic demands caused by
Fig. 5 Mean log-10 transformed testosterone and glucocorticoids excretion of eight males during the 4 -week birth season and the four week period immediately following the birth season (postbirth season). Asterisk indicates a significant difference at $P<0.05$, double asterisk at $P<0.01$
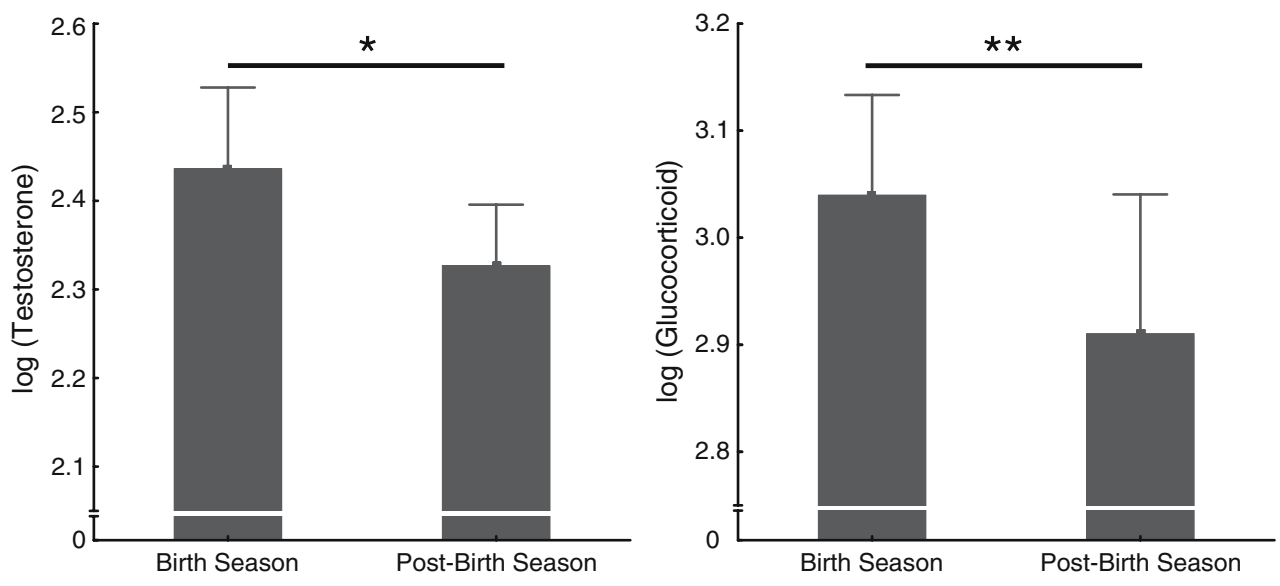


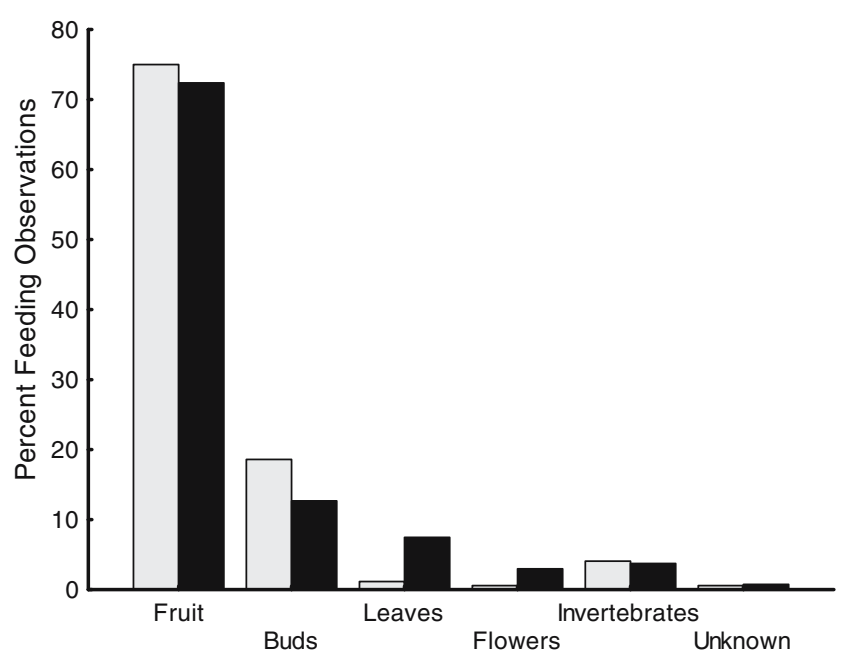

Fig. 6 Distribution of various food categories consumed during the birth season (gray bars) and the 4-week period directly following the birth season (PostBirth Season, black bars)

expenditures and costs associated with reproductive competition and mating, our finding of increased glucocorticoid production during this time period is also not surprising. Again, our data are in line with studies on several other seasonally reproducing primate species showing marked mating season elevations in glucocorticoid output (Schiml et al. 1996; Strier et al. 1999; Barrett et al. 2002; Lynch et al. 2002), including other lemur species (Lemur catta: (Pride 2005b), Propithecus verreauxi: (Fichtel et al. 2007). In contrast, our results of increased glucorticoid as well as testosterone levels during the birth season is unexpected and deviates from patterns found for example in Propithecus verreauxi, where birth season testosterone (Brockman et al. 1998; Brockman et al. 2001) and glucocorticoids (Fichtel et al. 2007) were significantly decreased compared to the mating season.

It is known that social as well as ecological factors may play an important role in modulating glucocortioid production (Romero et al. 2000; Muller and Wrangham 2004). As already mentioned, social instability has been identified as one of the major social factors influencing glucocorticoid levels in male primates (Sapolsky 1993; Bergman et al. 2005). In our study, however, group composition during the birth season was stable, and there were no changes in the dominance hierarchy during this period. Furthermore, rates of within-group aggression were not correlated with changes in glucocorticoid levels. Social challenges from outside (measured as rate of intergroup encounters) also did not reveal a significant effect on glucocorticoid levels. However, encounters might pose no risk because they are quite frequent (on average almost once per day), and usually nonaggressive because most often group members did not interact at all (Ostner et al. 2002).
In redfronted and ringtailed lemurs, episodic targeted aggression by two or more individuals against a group member typically of the same sex has been observed regularly (Vick and Pereira 1989; Pereira 1993). In captive ringtailed lemurs, targeted aggression among females peaked during the mating and birth season (Vick and Pereira 1989), which makes it relevant for our findings of birth season-related increases in glucocorticoid excretion. However, in redfronted lemurs, the seasonal pattern was less obvious, and in both species, most episodes involved females. All bouts of male targeted aggression occurred during the mating season, when male competition presumably is most intense (Vick and Pereira 1989). This lemurspecific phenomenon can therefore not explain the increase in glucocorticoids during the birth season in redfronted lemur males either.

In addition to social factors, ecological pressures, such as reduced food availability, predation risk, or climatic factors, have been reported to affect glucocorticoid output in a variety of species (Muller and Wrangham 2004; Weingrill et al. 2004). For several reasons, our results suggest that the observed increase in glucocorticoid levels during the birth season has social rather than ecological causes. First, predation rate in Kirindy redfronted lemurs is generally extremely low (six potential predation cases in three study groups between 1996 and 2000), and there is no obvious seasonal pattern in predation risk (Ostner and Kappeler, unpublished data). Second, the observed increase in glucocorticoid concentrations lasted for only 4 weeks before levels decreased again markedly. An ecological cause, e.g., low food availability, is not expected to be as extremely constrained in time (i.e., limited to a single month). Third, neither the amount of time the animals spent feeding, nor the composition of their diet, changed significantly between the birth season and the period immediately following it. In fact, the main food item (fruits of the species Astrotrichilia asterotricha) remained the same in both periods. A study on monthly fruit availability in Kirindy Forest (Bollen et al. 2005) also found no difference between birth and postbirth period in the proportion of monitored trees bearing juicy, fleshy fruits. The amount of these potentially preferable fruits increased significantly in December (Bollen et al. 2005), but this was well past the decline in glucocorticoids in our study males. Finally, testosterone and glucocorticoids followed a parallel pattern, which makes an ecological influence rather unlikely. In this respect, a study on chimpanzees revealed that short-term changes in food availability did also not lead to decreased androgen production, indicating that acute changes in testosterone were caused by social, rather than ecological factors (Muller and Wrangham 2005). Although ecological influences cannot completely be ruled out as an explanation for enhanced birth season androgen and 
glucocorticoid production in male redfronted lemurs, our data suggest that the simultaneous increase in both hormones were an effect of social rather than ecological challenges. However, to rigorously test the hypothesis of ecological influences on stress levels in this population, we clearly need more data on year-round food availability and energy budgets.

In our previous study on male androgen excretion, we proposed the post hoc explanation that the increased testosterone production during the birth season might enable males to stay aggressive during this predictable period of infanticide risk (Ostner et al. 2002). The present result of a parallel increase in glucocorticoids supports, but certainly cannot prove, this hypothesis. Infanticide is a viable male strategy also in annually reproducing species because the cessation of lactation may improve a female's physical condition and consequently also the survival prospects of the subsequent infant (Pereira and Weiss 1991). Although not directly observed in our study population, infanticide in redfronted lemurs has been observed in captivity and the wild, and always occurred in the first month postpartum (Jolly et al. 2000). Because redfronted lemur infants are weaned at an early age, the critical time window is limited to a short period following the birth of an infant until weaning. Due to pronounced seasonal reproduction, this time period is predictable for males, possibly allowing a male to prepare for the challenge. Increased glucocorticoids may aid in the defense against an incoming male because preparation for physical contest requires a condition in which the body is primed for mobilizing extra energy, which is one of the main actions of glucocorticoids (Sapolsky et al. 2000; Sapolsky 2002).

Such a possible link between increased male physiological stress and the risk of infanticide has also been proposed for chacma baboons (Bergman et al. 2005). Here, after the immigration of a new male into a baboon troop, males with a "friendship" with a lactating female showed an increase in glucocorticoids, whereas stress hormone levels stayed the same in males without a female friend. The authors concluded that this might occur because male friends are often the likely fathers of their friend's offspring and will hence need to defend the infant against other males. Unfortunately, we do not have any data on infanticidal attacks and male defense of infants in our study population. However, reproductive skew is high (Wimmer and Kappeler 2002) making it likely that dominant males need to defend infants. However, females mate with all resident males, effectively confusing paternity (Ostner and Kappeler 1999), which should prompt all potential fathers to defend infants against strange males. Under these circumstances, heightened androgen and glucocorticoid production in each male during the time when infants are born may be a proximate mechanism underlying an increase in individual male fighting ability and thus reduce the risk of infanticide.

\section{Conclusion}

In this paper, we investigated seasonal fluctuations in androgen and glucocorticoid excretion in male redfronted lemurs. The period with the greatest impact on testosterone and glucocorticoids were the mating season with its physiological and competitive challenges, as well as the birth season. Concerning the latter, we propose that the predictable risk of infanticide in this highly seasonal species has a major influence on male gonadal and adrenal endocrine activity. Several alternative social and ecological factors that have been reported to influence the production of the two hormone classes were investigated as well, but none of them can account for the observed pattern. To further investigate influences on glucocorticoid production in redfronted lemurs future studies should include measures of predation risk, possibly via an experimental set up, degree of feeding competition and seasonality of food abundance. Crucially, our analysis of seasonal stress in redfronted lemurs needs to be extended to females, which should be equally or even more targeted by most of the investigated social and ecological stressors.

Acknowledgments This study was conducted within a collaboration accord between the Laboratoire de Primatologie et de Biologie Evolutive de 1'Universite d'Antananarivo and the German Primate Center with the permission of the Directions des Eaux et Forets Madagascar and the Centre de Formation Professionelle Forestière in Morondava. We thank the late Prof. Berthe Rakotosamimanana, Dr. Rodin Rasoloarison and Léonard Razafimanantsoa for invaluable logistical support throughout this study. We are grateful to Mamitiana Razafindrasamba and Nielsen Rabarjiaona for their help with fecal sample collection, and to Dagmar Lorch for providing samples for the analysis of a possible storage effect. We thank Prof. Rupert Palme from the Institute of Biochemistry of the University of Veterinary Medicine in Vienna, Austria, for providing the glucocorticoid antibody and label used in this study. Andrea Heistermann and Jutta Hagedorn provided invaluable assistance with laboratory work. We thank Daniel Stahl for statistical advice and Oliver Schülke, Joanna Setchell and three anonymous reviewers for very helpful comments on the manuscript. Financial support was provided by the DFG (Ka 1082/4-1, 4-2). This study complies with the current laws of the countries in which it was conducted.

\section{References}

Abbott DH, Keverne EB, Bercovitch FB, Shively CA, Mendoza SP, Salzman W, Snowdon CT, Ziegler TE, Banjevic M, Garland TJ, Sapolsky RM (2003) Are subordinates always stressed? A comparative analysis of rank differences in cortisol levels among primates. Horm Behav 43:67-82

Alberts SC, Sapolsky RM, Altmann J (1992) Behavioral, endocrine, and immunological correlates of immigration by an aggressive male into a natural primate group. Horm Behav 26:167-178

Altmann J (1974) Observational study of behavior: sampling methods. Behaviour 49:227-267 
Angelier F, Weimerskirch H, Dano S, Chastel O (2007) Age, experience and reproductive performance in a long-lived bird: a hormonal perspective. Behav Ecol Sociobiol 61:611-621

Bales K, French J, McWilliams J, Lake R, Dietz J (2006) Effects of social status, age, and season on androgen and cortisol levels in wild male golden lion tamarins (Leontopithecus rosalia). Horm Behav 49:88-95

Barrett GM, Shimuzu K, Bardi M, Asabo S, Mori A (2002) Endocrine correlates of rank, reproduction, and female-directed aggression in male Japanese macaques (Macaca fuscata). Horm Behav 42:85-96

Baum M (2002) Neuroendocrinology of sexual behavior in the male. In: Becker J, Breedlove S, Crews D, McCarthy M (eds) Behavioral endocrinology, 2nd edn. The MIT Press, Cambridge, pp 153-204

Beehner J, Bergman T, Cheney D, Seyfarth R, Whitten P (2005) The effect of new alpha males on female stress in free-ranging baboons. Anim Behav 69:1211-1221

Bergman T, Beehner J, Cheney D, Seyfarth R, Whitten P (2005) Correlates of stress in free-ranging male chacma baboons, Papio hamadryas ursinus. Anim Behav 70:703-713

Bollen A, Donati G, Fietz J, Schwab D, Ramanamanjato J-B, Randrihasipara L, Van Elsacker L, Ganzhorn J (2005) An intersite comparison of fruit characteristics in Madagascar: Evidence for selection pressure through abiotic constraints rather than through co-evolution. In: Dew J, Boubli J (eds) Tropical fruits and frugivores. The search for strong interactors. Springer, Dordrecht, pp 93-119

Borries C (1997) Infanticide in seasonally breeding multimale groups of Hanuman langurs (Presbytis entellus) in Ramnagar (South Nepal). Behav Ecol Sociobiol 41:139-150

Brockman DK, Whitten PL, Richard AF, Schneider A (1998) Reproduction in free-ranging male Propithecus verreauxi: the hormonal correlates of mating and aggression. Am J Phys Anthropol 105:137-151

Brockman DK, Whitten PL, Richard AF, Benander B (2001) Birth season testosterone levels in male Verreaux's sifaka, Propithecus verreauxi: insights into socio-demographic factors mediating seasonal testicular function. Behav Ecol Sociobiol 49:117-127

Cavigelli SA (1999) Behavioural patterns associated with faecal cortisol levels in free-ranging female ring-tailed lemurs, Lemur catta. Anim Behav 57:935-944

Creel S (2001) Social dominance and stress hormones. Trends Ecol Evol 16:491-497

Crockett CM, Janson CH (2000) Infanticide in red howlers: female group size, male membership, and a possible link to folivory. In: van Schaik CP, Janson $\mathrm{CH}$ (eds) Infanticide by males and its implications. Cambridge University Press, Cambridge, pp 75-98

Dixson AF (1998) Primate sexuality: comparative studies of the prosimians, monkeys, apes, and human beings. Oxford University Press, Oxford

Drea C (2007) Sex and seasonal differences in aggression and steroid secretion in Lemur catta: Are socially dominant females hormonally 'masculinized'? Horm Behav 51:555-567

Engh A, Beehner J, Bergman C, Whitten P, Hoffmeier R, Seyfarth RM, Cheney DL (2006) Behavioural and hormonal responses to predation in female chacma baboons (Papio hamadryas ursinus). Proc R Soc Lond B 273:707-712

Fedigan L (2003) Impact of male takeovers on infant deaths, births and conceptions in Cebus capucinus at Santa Rosa, Costa Rica. Int J Primatol 24:723-741

Fichtel C, Kraus C, Ganswindt A, Heistermann M (2007) Influence of reproductive season and rank on fecal glucocorticoid levels in free-ranging male Verreaux's sifakas (Propithecus verreauxi). Horm Behav 51:640-648

Fowler J, Cohen L (1990) Practical statistics for field biology. Wiley, Chichester
Ganswindt A, Palme R, Heistermann M, Borragan S, Hodges J (2003) Non-invasive assessment of adrenocortical function in the male African elephant (Loxodonta africana) and its relation to musth. General and Comparative Endocrinology 134:156-166

Goodman SM, O'Connor S, Langrand O (1993) A review of predation on lemurs: implications for the evolution of social behavior in small, nocturnal primates. In: Kappeler PM, Ganzhorn JU (eds) Lemur social systems and their ecological basis. Plenum, New York, pp 51-66

Goymann W, Wingfield J (2004) Allostatic load, social status and stress hormones: The costs of social status matter. Animal Behaviour 67:591-602

Hausfater G (1975) Dominance and reproduction in baboons (Papio cynocephalus): a quantitative analysis. Contributions to Primatology $7: 1-68$

Heistermann M, Palme R, Ganswindt A (2006) Comparison of different enzymeimmunoassays for assessment of adrenocortical activity in primates based on fecal analysis. American Journal of Primatology 68:257-273

Hunt K, Wasser S (2003) Effect of long-term preservation methods on fecal glucocorticoid concentrations of grizzly bear and African elephant. Physiol Biochem Zool 76:918-928

Jolly A, Caless S, Cavigelli S, Gould L, Pereira ME, Pitts A, Pride RE, Rabenandrasana HD, Walker JD, Zafison T (2000) Infant killing, wounding and predation in Eulemur and Lemur. Int J Primatol 21:21-40

Kappeler PM, Pereira ME (2003) Primate life histories and socioecology. The University of Chicago Press, Chicago

Khan MZ, Altmann J, Isani SS, Yu J (2002) A matter of time: evaluating the storage of fecal samples for steroid analysis. Gen Comp Endocrinol 128:57-64

Kraus C, Heistermann M, Kappeler PM (1999) Physiological suppression of sexual function of subordinate males: a subtle form of intrasexual competition among male sifakas (Propithecus verreauxi)? Physiol Behav 66:855-861

Lynch J, Ziegler T, Strier K (2002) Individual and seasonal variation in fecal testosterone and cortisol levels of wild male tufted capuchin monkeys, Cebus apella nigritus. In: Hormones and Behaviour, vol 41, pp 275-287

Möstl E, Maggs J, Schrotter G, Besenfelder U, Palme R (2002) Measurement of cortisol metabolites in the faeces of ruminants. Vet Res Commun 26:127-139

Muller M, Wrangham R (2004) Dominance, cortisol and stress in wild chimpanzees (Pan troglodytes schweinfurthii). Behav Ecol Sociobiol 55:332-340

Muller M, Wrangham R (2005) Testosterone and energetics in wild chimpanzees (Pan troglodytes schweinfurthii). Am J Primatol 66:119-130

Nelson RJ (2000) An introduction to behavioral endocrinology, second edn. Sinauer Associates, Sunderland, MA

Ostner J, Heistermann M (2003) Endocrine characterization of female reproductive status in wild redfronted lemur females (Eulemur fulvus rufus). Gen Comp Endocrinol 131:274-283

Ostner J, Kappeler PM (1999) Central males instead of multiple pairs in redfronted lemurs, Eulemur fulvus rufus (Primates, Lemuridae)? Anim Behav 58:1069-1078

Ostner J, Kappeler PM (2004) Male life history and the unusual adult sex ratio in redfronted lemurs (Eulemur fulvus rufus) groups. Anim Behav 67:249-259

Ostner J, Kappeler PM, Heistermann M (2002) Seasonal variation and social correlates of androgen excretion in male redfronted lemurs (Eulemur fulvus rufus). Behav Ecol Sociobiol 52:485-495

Overdorff D (1998) Are Eulemur species pair-bonded? Social organization and mating strategies in Eulemur fulvus rufus from 1988-1995 in southeast Madagascar. Am J Phys Anthropol 105:153-166 
Palme R, Möstl E (1997) Measurement of cortisol metabolites in faeces of sheep as a parameter of cortisol concentration in blood. Zeitschrift für Säugetierkunde. Int J Mammal Biol 62 192-197

Pereira ME (1993) Agonistic interactions, dominance relation, and ontogenetic trajectories in ringtailed lemurs. In: Pereira ME, Fairbanks LA (eds) Juvenile primates: life history, development, and behavior. Oxford University Press, New York, pp 285-305

Pereira ME, Kappeler PM (1997) Divergent systems of agonistic behaviour in lemurid primates. Behaviour 134:225-274

Pereira ME, Weiss ML (1991) Female mate choice, male migration, and the threat of infanticide in ringtailed lemurs. Behav Ecol Sociobiol 28:141-152

Pereira R, Duarte J, Negrão J (2006) Effects of environmental conditions, human activity, reproduction, antler cycle and grouping on fecal glucocorticoids of free-ranging Pampas deer stags (Ozotoceros bezoarticus bezoarticus). Horm Behav 49:114-122

Pinheiro J, Bates D (2000) Mixed effect models in S and S-Plus. Springer, New York

Pope T (1990) The reproductive consequences of male cooperation in the red howler monkey: paternity exclusion in multi-male and single-male troops using genetic markers. Behavioral Ecology and Sociobiology 27:439-446

Pride R (2005a) Foraging success, agonism, and predator alarms: behavioral predictors of cortisol in Lemur catta. Int J Primatol 26:295-319

Pride R (2005b) Optimal group size and seasonal stress in ring-tailed lemurs (Lemur catta). Behav Ecol 16:550-560

Rasoloarison RM, Rasolonandrasana BPN, Ganzhorn JU, Goodman SM (1995) Predation on vertebrates in the Kirindy forest, western Madagascar. Ecotropica 1:59-65

Romero L, Reed J, Wingfield J (2000) Effects of weather on corticosterone responses in wild free-living passerine birds. Gen Comp Endocrinol 118:113-122

Rommerts F (1998) Testosterone: An overview of biosynthesis, transport, metabolism and nongenomic actions. In: Nieschlag E, Behre $\mathrm{H}$ (eds) Testosterone. Action-Deficiency-Substitution, 2nd edn. Springer, Berlin, pp 1-31

Sapolsky R (1983) Endocrine aspects of social instability in the olive baboon (Papio anubis). Am J Primatol 5:365-379

Sapolsky RM (1993) The physiology of dominance in stable versus unstable social hierarchies. In: Mason WA, Mendoza SP (eds) Primate social conflict. SUNY Press, Albany, pp 171-204
Sapolsky R (2002) Endocrinology of the stress-response. In: Becker J, Breedlove S, Crews D, McCarthy M (eds) Behavioral endocrinology, 2nd edn. The MIT Press, Cambridge, pp 409-450

Sapolsky R, Romero L, Munk A (2000) How do glucocorticoids influence stress responses? Integrating permissive, suppressive, stimulatory, and preparative actions. Endocr Rev 21:55-89

Schiml P, Mendoza S, Saltzman W, Lyons D, Mason W (1996) Seasonality in squirrel monkeys (Saimiri sciureus): Social facilitation by females. Phys Behav 60:1105-1113

Sorg JP, Ganzhorn JU, Kappeler PM (2003) Forestry and research in the Kirindy Forest/Centre de Formation Forestiere Professionèlle. In: Goodman SM, Besnstead JP (eds) The natural history of Madagascar. University of Chicago Press, Chicago, pp 1512-1519

Strier KB, Ziegler TE, Wittwer DJ (1999) Seasonal and social correlates of fecal testosterone and cortisol levels in wild male muriquis (Brachyteles arachnoides). Horm Behav 35:125-134

Vick LG, Pereira ME (1989) Episodic targeting aggression and the histories of Lemur social groups. Behav Ecol Sociobiol 25:3-12

Weingrill T, Gray D, Barrett L, Henzi S (2004) Fecal cortisol levels in free-ranging female chacma baboons: relationship to dominance, reproductive state and environmental factors. Horm Behav 45:259-259

Wickings EJ, Marshall GR, Nieschlag E (1986) Endocrine regulation of male reproduction. In: Dukelow WR, Erwin J (eds) Comparative Primate Biology. Alan R. Liss, New York, pp 149-170

Wimmer B, Kappeler PM (2002) The effects of sexual selection and life history on the genetic structure of redfronted lemur, Eulemur fulvus rufus, groups. Anim Behav 64:557-568

Wingfield JC, Hegner RE, Dufty AMJ, Ball GF (1990) The "challenge hypothesis": theoretical implications for patterns of testosterone secretion, mating systems, and breeding strategies. Am Nat 136:829-846

Wingfield J, Jacobs J, Tramontin A, Perfito N, Meddle S, Meaney D, Soma K (2000) Toward and ecological basis of hormonebehavior interactions in reproduction of birds. In: Wallen $\mathrm{K}$, Schneider J (eds) Reproduction in context - social and environmental influences on reproduction. The MIT Press, Cambridge, pp 85-128

Ylönen H, Eccard J, Jokinen I, Sundell J (2006) Is the antipredatory response in behaviour reflected in stress measured in faecal corticosteroids in a small rodent? Behav Ecol Sociobiol 60:350 358 